\title{
Understanding Direct Mail Letters as a Genre
}

\author{
Thomas A. Upton
}

\begin{abstract}
What makes non-profit, philanthropic discourse so persuasive has not been well explored to date. Using a specialized corpus of direct-mail letters from philanthropic organizations in five different fields, this study seeks to combine the tools of corpus analysis with the specificity of genre analysis in a way that has not been done before to provide a new perspective on a genre that is not well understood. The underlying goal is to look for a methodology that will provide much of the qualitative detail that is common to genre analysis while at the same time provide the reliability that is best assured by the quantitative power of computerized corpus analysis. Using Bhatia's approach to genre analysis (1993) and his exploratory efforts in investigating fundraising discourse (1997, 1998) as a foundation, key patterns in the rhetorical structure of direct-mail letters revealed through a large-scale corpus analysis are presented.
\end{abstract}

\section{Background}

Philanthropic discourse is quite fascinating to study. Indeed, Bhatia (1998) claims that the discourse of fundraising represents one of the most dynamic forms of language use. "For a relatively limited number of communicative functions, this discourse form offers a large variety of creative options, some rarely used before. It is a category of genre that offers an interesting and challenging profile of linguistic realizations to achieve a limited set of generic objectives” (Bhatia, 1998, p. 100).

The dynamic nature of philanthropic discourse is due to the fact that it is designed to be quite persuasive. In short, its primary purpose is to persuade people to contribute to worthy causes or to underwrite philanthropic programs (Connor, 2000). Because of its persuasive purposes, fundraising has a great deal in common with promotional materials such as sales letters and job applications, in which the purpose is to make a sale: in sales letters, a service or product; in letters of application, a person's abilities; in fundraising, a worthy cause (Bhatia, 1993; Connor \& Wagner, 1998).

Recent studies of philanthropic discourse, specifically fund-raising texts, have for the most part employed a qualitative approach, analyzing characteristics such as communicative functions (Bhatia, 1997; Connor, 1997), rhetorical patterns (Abelen, Redeker \& Thompson, 1993; Crismore, 1997; Lauer, 1997) social contexts (Bazerman, 1997; Myers, 1997), metaphors (McCagg, 1997), and cultural differences (Connor \& Wagner, 1998; Graves, 1997). Although these studies have contributed to our understanding of the language of fund raising, the qualitative nature of these studies leaves us still without an empirical baseline for comparing the general features of fundraising texts with those of other common texts.

What is missing is a large, quantitative, corpus-based study of fundraising texts to develop such a baseline. The Indiana Center for Intercultural Communication (ICIC), with funding from and in cooperation with the Indiana University Center on Philanthropy, has begun a concerted effort to 
carefully study the language of fundraising by collecting a large corpus of fundraising material. The study discussed in this paper presents an analysis of some of the rhetorical features of the direct-mail letters that are included in the ICIC Fundraising Corpus.

Further, this study seeks to combine the tools of corpus analysis with the specificity of genre analysis in a way that has not been done before to provide a new perspective on a genre that is not well understood. The underlying goal is to look for a methodology that will provide much of the qualitative detail that is common to genre analysis while at the same time providing the reliability that is best assured by the quantitative power of computerized corpus analysis.

\section{The Genre of Direct Mail Letters}

\subsection{Direct Mail Letters}

"Direct mail" is the term used to describe the letters sent out by philanthropic organizations in an effort to raise funds for support. In many respects, these letters are not unlike the promotional direct-mail sales letters sent out by businesses (Abelen, Redeker, and Thompson, 1993; Bhatia, 1998). Direct mail is a huge business in the U.S., and there are few nonprofit organizations that do not use the direct mail medium in one way or another (Torre and Bedixen, 1988). As Abelen, Redeker, and Thompson (1993) point out, the direct mail letter is the "most important instrument for communicating the 'good cause' of a non-profit organization to a wide range of prospective donors" (p. 325). It is in this letter that the prospective donor has to be persuaded to give money. In a small scale study comparing Dutch and American direct mail letters, Abelen et al (1993) show that direct mail letters do follow general persuasive strategies which can vary from culture to culture. It is the intent of this study to define those patterns in fund raising letters that previous research, such as Abelen et al (1993), began to chart. The approach taken here is based on genre analysis.

\subsection{Genre Analysis: Language Description as Explanation}

Discourse analysts, such as Bhatia (1993), note that discourse analysis, the study of language use beyond sentence boundaries, can be conducted using at least four levels of description. The first is by focusing on surface-level linguistic description, noting for example the frequency of certain syntactic features of different varieties of English. The second is the use of functional language description. Here the aim is to investigate the relationship between grammatical choice and rhetorical function. The third approach is using interactional analysis, which highlights the interactive nature of discourse between the text and the reader.

Bhatia (1993) finds these first three approaches inadequate on two fronts. First, they lack "adequate information about the rationale underlying various discourse-types," including "insufficient explanation of socio-cultural, institutional, and organizational constraints and expectations that influence the nature of a particular discourse-genre" (p. 10). Second, they pay "little attention to the conventionalized regularities in the organization of various communicative events" (p. 10). Instead, Bhatia argues that 
when analyzing text discourse, a fourth approach--genre analysis--is most fruitful. In his words, "it is necessary to combine socio-cultural...and psycholinguistic...aspects of text construction and interpretation with linguistic insights in order to answer the question, 'Why are specific discourse-genres written and used by the specialist communities the way they are?’” (p. 11).

Drawing on Swales (1981, 1990), Bhatia (1993) describes genre as having the following characteristics: (1) it represent a recognizable communicative event characterized by a set of communicative purpose; (2) it is identified and mutually understood by members of the professional or academic community in which it regularly occurs; (3) it is usually a highly structured and conventionalized communicative event; and (4) it is bound by constraints (e.g., structural, linguistic) that are readily noticed when broken. In short, Bhatia argues that

"each genre is an instance of a successful achievement of a specific communicative purpose using conventionalized knowledge of linguistic and discoursal resources” (p. 16).

\subsection{Rhetorical Structures of Genre and Corpus Linguistics}

Traditional genre analysis proposes "moves," or functional components, as basic elements of a genre (Swales 1990); indeed, it is argued that such moves can be taught to a novice writer of a particular genre (Dudley-Evans 1995). According to Bhatia (1993), cognitive structuring in a genre is the property of the genre and not that of the reader. This structuring depends on the communicative purpose(s) that it serves in the genre, and is the reason why one genre varies from another. In persuasive discourse, Connor and Mauranen (1999) and Connor (2000) have already shown that a moves-based analysis can be successfully applied to the analysis of grant proposals.

That genre expectation varies from genre to genre has important ramifications on the growing field of corpus linguistics. The goal of corpus linguistics is to investigate the way people use language by analyzing large databases of real language examples (Biber, Conrad, \& Reppen 1998). However, most current language corpora are eclectic collections of spoken and written text from a wide variety of native-language contexts. Although many of these corpora are quite large and much can be discerned about the general lexical and grammatical features of a language from them, they offer little insight into the moves expectations of individual genres that may make up the larger corpus.

Genre analysis argues first of all that attention to writing for specific purposes is crucial since particular tasks require additional strategies beyond general writing ability. Furthermore, knowing the situation, context, and stimulus is important since these may elicit different types of language based on the purpose and genre. Consequently, we need corpora that are limited to specific genres and that include the writing requirements and the contexts in which the texts are generated. Connor and Mauranen (1999), in their genre analysis of a corpus of grant proposals, provide one recent example of how a genre concept can be applied to a specialized corpus analysis.

Furthermore, as Flowerdew (1998) points out, a great deal of the corpus-based, applied analysis of texts has focused on lexico-grammatical patterning, producing collocations and lists of fixed phrases. Much of this work has centered on the propositional level of texts with less regard to functional and rhetorical aspects. For practical purposes, however, instead of producing simple lists of modals and hedges, for example, it would be beneficial to show how modals are used persuasively in specific 
sections of a direct mail letter, as in politely requesting a donation. A promising direction, according to Flowerdew, will be tagging not only lexicon and syntax, which are the traditional strategies in corpus analysis, but also discourse features such as moves. In Flowerdew's words: “Another suggestion, which I believe would have wide pedagogical applications, is more exploitation of the tagging function of existing software on the market. As Leech (1991) remarks most of the work on text annotation (tagging) has been done at the grammatical (word class) or syntactic (parsing) level. Very little has been done on the semantic or pragmatic discourse level to date. For example, text could be tagged manually to indicate the generic 'move structures' such as background, scope, purpose in the introductory sections of a report” (Flowerdew 1998: p. 549).

\section{Goals for this Study}

This study attempts to combine the power of corpus analysis with the specificity of genre analysis in a way that has not been done before with a genre that is important, but not well understood. This was done in three steps: (1) collecting a large genre-specific corpus of direct mail letters, (2) analyzing and tagging the rhetorical moves, and (3) using computerized database and concordancing software to investigate the patterns of discourse that underlie this genre. The primary research question for this study was to dediscern the genre characteristics of fund raising letters.

\section{Method}

\subsection{The Corpus}

The Indiana Center for Intercultural Communication (ICIC), with a research grant from the IU Center on Philanthropy, is in the final stages of completing a three million word corpus--the ICIC Fundraising Corpus--that will include direct mail letters, case statements, annual reports, and grant proposals from 300-500 non-profit organizations. These organizations, of various sizes, represent the following fields: health and human services, arts and culture, environment, community development, and education. The data used for this study, drawn from the above corpus, included 242 direct mail letters from 71 organizations and comprised a total of 146,693 words. Each letter was scanned into a computer and double-checked for accuracy. Each letter was coded to indicate non-profit field, organization, and organization size (based on income). This information was obtained through questionnaires and interviews conducted with most of the agencies represented in the corpus.

\subsection{Moves and Structural Elements}

Bhatia (1998), in a paper comparing corporate and philanthropic advertising given at an international symposium on the discourse of fundraising (Indianapolis, August 1998), began looking at the genres that make up fundraising discourse. In analyzing samples of direct mail fundraising letters, he noted that 
they appear to have a relatively simple six-move discourse structure. These six moves are (1) establishing credentials, (2) introducing the cause, (3) offering incentives, (4) enclosing brochures, (5) soliciting support, and (6) expressing gratitude. He notes, however, that his analysis "has been based on a limited set of data from a specific cultural context...A more informed discussion...will require a more comprehensive, rigorous, and sustained analysis of data” (Bhatia, 1998, p. 110).

Using a comprehensive, rigorous, and sustained analysis of data, a research team, including the present researcher, other ICIC researchers, and research assistants, tested Bhatia's six-move discourse structure to see if it could be applied to a large corpus of direct mail letters. In a pilot study involving 20 letters, several modifications to Bhatia's (1998) proposed genre structure for direct mail letters were deemed necessary. First, it was obvious that there were two additional rhetorical moves that needed to be added, as their presence did not seem to be infrequent. The first additional move we called "get attention." The communicative, functional purpose of this move was to get and focus the reader's attention at the start of the letter. Typical strategies for doing this were to start with a quotation of some sort, a shocking or unexpected statement, or to offer some type of general pleasantries. The second move we added to the six that Bhatia described for direct mail letters comes at the end of many of the letters. The communicative function of this move is to bring the letter to a pleasant close and includes statements such as, "I hope you have a nice day." We called this move "conclude with pleasantries."

Besides the addition of these two moves, we made one further major change to Bhatia's original sixmove genre structure. In practice, we found it impossible to distinguish in a reliably consistent way the genre functions that Bhatia calls "establishing credentials" and "introducing the cause." These two functions were so tightly intertwined in many of the letters we looked at in our pilot study that we were unable to consistently differentiate them. Indeed, when one looks at them more closely, it is easy to see that these two moves have much in common. In "establishing credentials," the goal is to highlight what the organization does, and the contribution it can make; in "introducing the cause," the goal is to highlight the need that the organizations seeks to address. But for many non-profit organizations, their primary or even sole purpose is to address a particular need; they talk about who they are and what they do in the context of what the cause is. Consequently, we found it necessary to collapse these two moves proposed by Bhatia into one move, which we call "introduce the cause and/or establish credentials of organization.”

We also made a couple of relatively minor adjustments to three of the other moves proposed by Bhaia. One common move noted by Bhatia was one he called "soliciting support." We observed, however, that many letters not only requested support but also some other type of response, such as volunteering to help or contacting the organization for further information. Consequently, we decided to change the name of this move to "solicit response" and include two sub-moves, soliciting financial support and soliciting other response.

Further, when looking at the direct mail letters in our corpus, it became clear that two of the moves, "offer incentives" and "reference insert," were often embedded in other moves. Take, for example, the following sentence: "Please fill out the enclosed card to send in your tax-deductible contribution to help support the boys and girls at Camp X.” The primary_function of this sentence is soliciting support, but there are two other functions it seeks to accomplish: bringing attention to the enclosure and offering an incentive for contributing ("tax-deductible”). We decided to view this sentence and 
others like it as containing three moves: the primary move of soliciting support and the embedded moves of "referencing insert" (which Bhatia calls "enclosing brochure") and "offering incentive." Consequently, we recognized the two moves "referencing insert" and "offering incentive" as being capable of either standing alone or being embedded in other moves.

With the changes and modifications described above, the basic moves that we see as describing the discourse of direct mail letters are: 1) get attention, 2) introduce the cause and/or establish credentials of organization, 3) solicit response, 4) offer incentive, 5) reference insert, 6) express gratitude, and 7) conclude with pleasantries. These are outlined in Table 1. An example of each Move in the context of a direct mail letter can be seen in Appendix 3.

Lastly, we decided to also look at the structural elements that are frequently found in direct mail letters to see what role they might play in the persuasive appeal of these letters. While these components of the direct mail letters were not originally included in Bhatia's (1998) genre analysis, many instructional materials designed to train writers specifically address and stress the importance of using these various elements to make direct mail letters more persuasive (e.g., Cone 1987, Lewis 1997). Consequently, as practitioners view these structural elements as an important part of the direct mail letter, and they are intended to have an impact on the reader, they seemed worth examining.

[This space left blank intentionally] 
Table 1

$\underline{\text { Revised move features of non-profit direct mail fundraising letters }}$

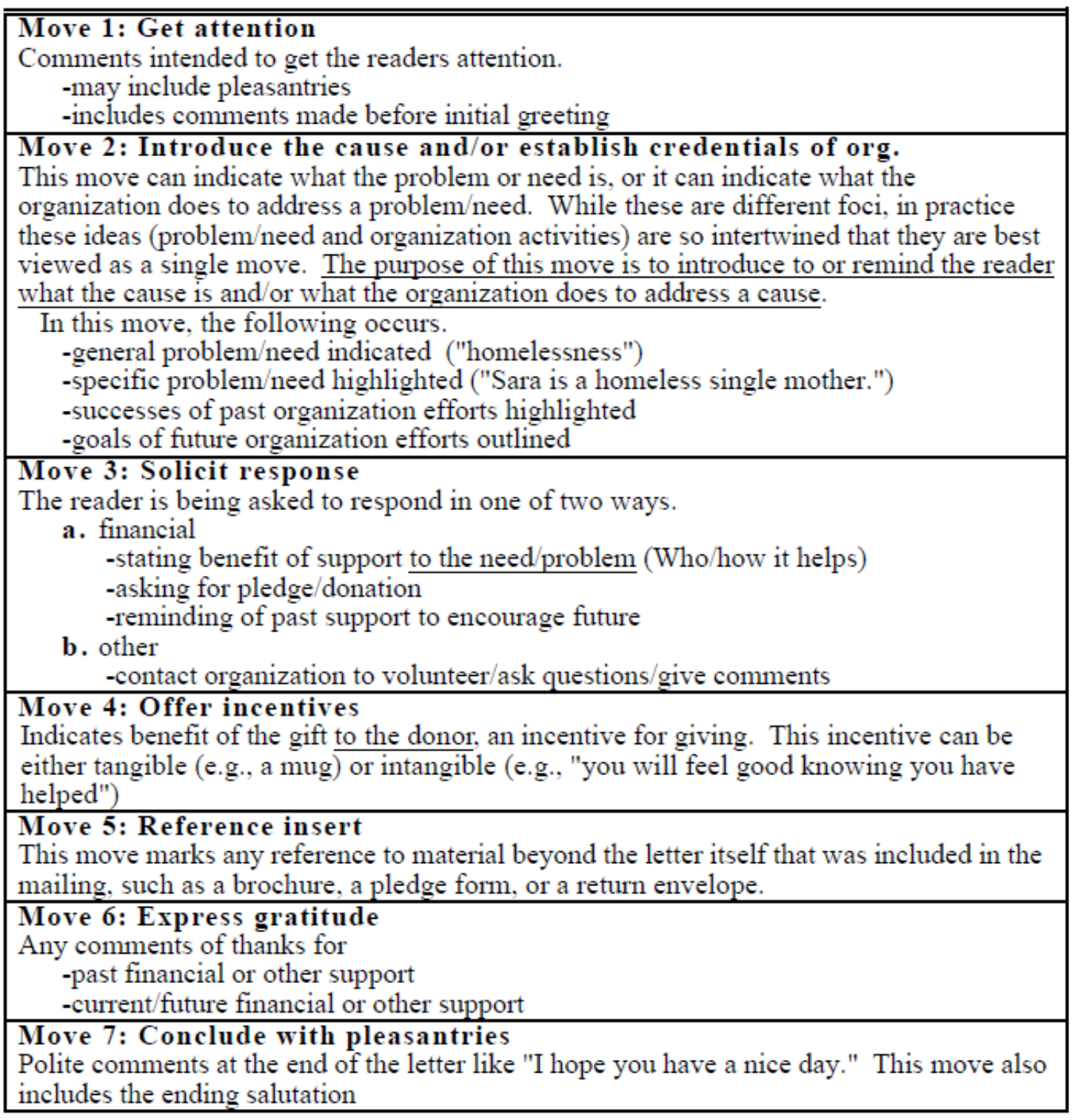




\subsection{The Analysis}

Using the rubrics given in Table 1 outlining the rhetorical moves of the direct mail letters and in Table 2 outlining the structural elements, two raters hand-coded all 242 letters in the corpus. Interrater reliability was calculated at $84 \%$, with all discrepancies reconciled through discussion. The vast majority of discrepancies that occurred between the two raters resulted from initial disagreement as to where one move ended and the next started, not as to the presence of a particular move. This interrater reliability is quite good, since, as Bhatia (1993) notes, there are sometimes "cases which will pose problems and escape identification or clear discrimination, however fine a net one may use. After all, we are dealing with the rationale underlying linguistic behavior rather than its surface form” (p. 93). Once all of the moves were agreed upon and marked, each letter was then tagged to indicate the start and stop of each move in each text.

The presence and sequence of each move and structural element for each text was also catalogued in an Excel file. This allowed us to keep track of the total frequency of each move in the corpus, the relative location it occurred in each letter (e.g., first, second, third), what other moves a move most commonly occurred with, how frequently a move was embedded in another move, and how frequently a move occurred in the body of the text as opposed to in a postscript.

[This space left blank intentionally] 
Table 2

Direct Mail "Structural Elements"

Element A: Date line

The date when the letter was written/sent is given. E.g., January 10, 1998

Element B: Address information

The address of the addressee is given. This provides a level of formality to the letter.

E.g., Joy Us Donor

123 Boulevard Road

Here, There 45678

Element C: Salutation

This is the opening greeting of the letter and is followed either by no punctuation, a comma, or a colon.

E.g., Dear Joy Donor,

Element D: Complimentary Close

This is the word or phrase that draws the letter to a close and is followed by either a comma or no punctuation.

E.g., Sincerely,

Sincerely yours

On behalf of our clients,

Element E: Signature

This is the author's penned signature.

Element F: Signature footer

This provides the printed name of the letter signer and/or the title of the signer.

E.g., $\quad$ Nahn Prophet

President I

Element G: Footnote information

This is information located after everything else in the letter and indicates that there is other information the reader should be aware of. Examples include "enclosure" and "cc". 


\section{Results}

\subsection{Move Frequencies and Lengths}

Table 3 provides summary information about the moves in this corpus of 242 direct mail letters, including the frequency of each move, the rate of multiple occurrences of moves within letters, and the average number of words per move. Not surprisingly, the most common move in all of these letters was Move 3 "Solicit Response," which occurs 546 times. This represents 39\% of all the moves occurring in this corpus, showing up at the rate of 2.3 times per letter. In fact, of the 242 letters, only six letters did not have at least one Move 3 occurring at some point in the letter, with Move 3 represented in $97 \%$ of the letters. The second most common move was Move 2 "Introduce the cause and/or establish credentials of the organization," which occurred 362 times. At the rate of 1.5 times per letter, this move represents $26 \%$ of all the moves in this corpus. Move 2, like Move 3, also clearly seems to be a required move in this genre as it occurs in $93 \%$ of the letters. Move 4 ("Offer Incentive) at 8.1\%, Move 5 ("Reference Insert") at 11.0\%, and Move 6 ("Express Gratitude”) at $10.7 \%$ occurred at relatively similar rates of frequency across the 242 letters. While apparently optional moves within this genre, each occurred fairly frequently. Move 4 was represented at least once in 35\% of the letters, Move 5 occurred in 52\% of the letters, and Move 6 occurred in $51 \%$ of the 242 letters.

Table 3

Move totals, percentages and rates of occurrence

\begin{tabular}{lrrrrrrc}
\hline & Move 1 & Move 2 & Move 3 & Move 4 & Move 5 & Move 6 & Move 7 \\
Moves & & & & & & & \\
$\quad$ Total Number & 35 & 362 & 546 & 113 & 153 & 148 & 33 \\
$\quad \%$ of total & $2.5 \%$ & $26.0 \%$ & $39.3 \%$ & $8.1 \%$ & $11.0 \%$ & $10.7 \%$ & $2.4 \%$ \\
$\begin{array}{l}\text { Letters } \\
\text { w } / \geq 1 \text { occurrence }\end{array}$ & 35 & 226 & 236 & 85 & 127 & 124 & 31 \\
$\quad \%$ of total & $15 \%$ & $93 \%$ & $97 \%$ & $35 \%$ & $52 \%$ & $51 \%$ & $13 \%$ \\
$\quad \begin{array}{l}\text { Words/move } \\
\text { Avg. }\end{array}$ & 39 & 150 & 48 & 29 & 9 & 10 & 10 \\
\hline
\end{tabular}

Move 1 (“Get attention”) and Move 7 (“Conclude with pleasantries”) were clearly icing-on-the-cake moves that writers of this genre could draw upon when desired but did not do so very frequently. Move 1 represented 2.5\% of the moves in this corpus and occurred in only 15\% of the letters. Similarly, Move 7 represented 2.4\% of the moves in this corpus and occurred in only 13\% of the letters. Using the concordance program Wordsmith (Oxford University Press, 1998), it is possible to analyze and compare the lengths of each of the moves. Move 2 is by far the longest move in this genre, averaging 150 words per occurrence. Move 3, the second longest move, is only 1/3 the length at 48 words per occurrence. Moves 5, 6 and 7 are the shortest, with Move 5 averaging 9 words per occurrence, and Moves 6 and 7 averaging 10 words per occurrence. Table 5 provides the average words per occurrence for each of the seven moves in this genre. 


\subsection{Move Positions}

Of equal interest to how frequently the individual moves occurred in the genre of direct mail letters and their relative lengths is where they occurred relative to each other in the letter. The location of two of the moves turns out to be quite predictable. Although Moves 1 and 7 did not occur very frequently, when they were present Move 1 occurred as the initial move in the letter $97 \%$ of the time, and Move 7 occurred as the final move before the complimentary close $100 \%$ of the time.

Also predictable to a very great extent are the positions of Moves 2 and 3. If one ignores the presence of Move 1, Move 2 occurs as the initial move in the direct mail letter $74 \%$ of the time. And Move 2, regardless of its position in the letter, is immediately followed by Move $387 \%$ of the time. Another interesting feature about Move 3 is that 25\% of these moves had either a Move 4 or a Move 5 , or both, embedded in them, which represented $50 \%$ of the combined occurrences of these two moves in the corpus. Of the remaining 132 combined occurrences of Moves 4 and 5, they immediately followed Move $360 \%$ of the time. Move 6 is probably the most flexible of the moves occurring, when it does, with nearly equal frequency towards the beginning, middle, and end of the letter.

One last observation about the position of the moves within direct mail letters is their presence in a postscript (P.S.) occurring after the signature. Of the 242 letters, 36\% had a postscript, with all the moves except Move 1 appearing here. By far the most common move in the postscript is once again Move 3, which not only makes up 49\% of the moves that occur here but also occurs in $78 \%$ of the letters having a postscript. The remaining moves in the postscript are fairly evenly distributed among Move 2 (11\%), Move 4 (15\%), Move 5 (14\%), and Move 6 (9\%). Of the letters with a postscript, $51 \%$ had only one move in the P.S., $33 \%$ had two moves, and $16 \%$ had three or more moves.

[This space left blank intentionally] 


\subsection{Structural Elements}

Table 4 shows the relative frequency of each of the structural elements (see Table 2) of the direct mail letters in this corpus.

\section{Table 4}

\section{$\underline{\text { Percentage of letters with each structural element }}$}

\begin{tabular}{|l|c|}
\hline Structural Elements & $\begin{array}{l}\text { Percent of } \\
\text { Letters }\end{array}$ \\
\hline \hline Element A: Date Line & $77 \%$ \\
\hline Element B: Address Information & $51 \%$ \\
\hline Element C: Salutation & $88 \%$ \\
\hline Element D: Complimentary Close & $90 \%$ \\
\hline Element E: Signature & $89 \%$ \\
\hline Element F: Signature Footer & $87 \%$ \\
\hline Element G: Footnote Information & $7 \%$ \\
\hline
\end{tabular}

The vast majority of the letters in this corpus contained four structural elements, an opening salutation (88\%), a complimentary close $(90 \%)$, a signature (89\%), and a typed signature footer (87\%). Occurring in most letters, but appearing to be more optional were the date line (77\%) and Address Information (51\%). It appears that footnote information is included relatively infrequently (7\%).

\section{Discussion}

Based on the results of the genre analysis of the 242 direct mail letters in this corpus, a couple of observations can be made about how moves are used within the genre. First of all, the corpus techniques have shown that some of the moves originally identified by Bhatia (1998) appear to be obligatory in the genre, while others are seem to be merely optional. Secondly, it seems clear that the juxtaposition of the moves relative to each other shows meaningful patterns. Move 2 (Introduce the cause and/or establish credentials of organization) and Move 3 (solicit response) both appear to be required moves in this genre. The preeminence of these two moves can be seen by the fact that not only do they occur in nearly every direct mail letter in the corpus, but they generally occur more than once, they usually occur as the first and second moves in the letter, they are by far the longest of the moves, and they almost always occur in juxtaposition to each other.

That Moves 2 and 3 are the most significant - in frequency, size, and position in the letter - is not surprising. At its most basic level, the purpose of the direct mail letter is to tell the readers who the 
organization is and/or what the need is, and to request funds to help the cause. These functions are accomplished in these two moves. The other five moves serve, then, as optional tools that individual writers in this genre can incorporate in various ways to tailor the effect of the letter on the reader.

For example, Moves 4 and 5 clearly play a secondary role in the direct mail letter as they tend to be quite short in length and as often as not are embedded in another move, usually Move 3. Nevertheless, their role appears to be an important one in that they are included in a sizeable percentage of the letters (Move 4 in 35\%; Move 5 in 53\%). Essentially, it seems their function is to serve as a reminder. In the case of Move 4, the readers most often are reminded either that contributions to non-profit organizations are tax-deductible, or that they will "feel good" about the contribution that they make. With Move 5, the function of this move is simply to remind the readers to look at other material that has been included with the letter.

Move 6, occurring in 51\% of the letters, also plays an important role of informing the readers how much the organization appreciates their support. Nevertheless, this role is noticeably a secondary one when the frequency, number of occurrences and length of this move are considered in relation to Moves 2 and 3. Moves 1 and 7 are clearly optional moves, with both of them occurring in fewer than $15 \%$ of the letters.

Similar observations can be made about the structural elements that are included; clearly there are some that are considered obligatory, such as the salutation and complementary close, and others that are more optional, such as address information. The fact that most of these structural elements occur in most direct mail letters, and that practitioners themselves view these as essential components of the direct mail letter (e.g., Cone 1987) suggest that more careful analysis of these may be warranted in future studies. Indeed, it could be argued that at least some of these elements should be viewed as moves in themselves, as they are functional units of text serving a specific purpose that adds to the persuasive nature of the letters. Textual choices within these structural elements, for example how to phrase the salutation, are actually quite significant and can be viewed as something beyond a standardized template.

One strength of this type of corpus analysis is that it allows us to develop prototypes of the genre. Three such prototypes suggest themselves from these data. The first prototype, shown in Appendix 1 , represents the most basic form of the direct mail letter, using the moves and structural elements which occur in at least 85\% of the letters in the corpus. These include Moves 2 and 3, and Structural Elements C, D, E, and F. The second prototype, which is given in Appendix 2, includes all the moves and the structural elements that occurred in over $50 \%$ of the letters in this corpus. These include Moves 2, 3, 5 and 6 as well as Structural Elements A, B, C, D, E and F. In this letter, each of these moves is represented by the average number of times the move occurred per letter (rounded to the nearest whole number) in the corpus as well as by their most common positions in the letter. The third prototype, given in Appendix 3, simply shows what a direct mail letter would look like if it used each of the possible moves and structural elements that define this genre. However, only one letter in the entire corpus used all seven possible moves, and it only used six of the seven structural elements. 


\section{Conclusion}

A primary goal for this study was to explore the promise of combining the tools of corpus analysis, which are more typically focused on lexico-grammatical features of texts, with the functional and rhetorical focus of genre analysis. This marriage of approaches appears to be one that will prove to be very fruitful, providing much of the qualitative detail common to genre analysis - allowing us to answer questions about how texts are structured and organized and why - while at the same time offering the reliability that is best assured by the quantitative power of computerized corpus analysis.

Combining the tools of corpus and genre analysis in this study, we find that the genre of direct mail fundraising letters does indeed live up to this billing as representing a very dynamic form of language use offering many creative options. Nevertheless, like all genres, there is clearly an inherent, coherent structure that defines it, although this genre may offer more flexibility in its structure than many. Representative of this flexibility appears to be the fact that there may be variability in move sequencing and length between direct mail letters written by organizations representing different non-profit fields. For example, preliminary analysis seems to indicate Move 2 not only occurs more frequently, but tends to be longer in letters written by Health and Human Services organizations than for those written by Educational organizations. Future research on this corpus will seek to explore the ways that different fund raising fields may use common moves in different ways to appeal to their specific audiences.

Although it appears that the genre structure for direct mail letters that has been proposed here is a robust one that readily accounts for the wide variety of letters that make up this corpus, this analysis offers little insight into how these moves are realized linguistically. For example, are there common surface-level linguistic features common to this genre? What is the relationship between grammatical choice and rhetorical function? How is persuasive appeal - rational, credibility, and affective - operationalized in this genre? While this structural analysis is an important first step toward understanding what makes a strong and persuasive direct mail letter, this knowledge will benefit practitioners most when we can also discuss and provide examples of the common linguistic features of these letters. As we continue our analysis of the direct mail letters in the ICIC Fundraising Corpus, these are the questions that we will be seeking to answer.

\section{ACKNOLEDGEMENT}

I would like to give special thanks to Ulla Connor, the Director of ICIC, for her inspiration, comments and suggestions throughout this research project and on the various drafts of this paper. Many thanks also to Steve LeBeau, whose Herculean efforts to organize and maintain the ICIC Fundraising Corpus made this study possible, and to Kim Strapulous, Kostyantyn Gladkov, and Caroline Besore Kirk for their assistance on coding, entering and manipulating data for the hundreds of letters in the corpus. 


\title{
Appendix 1
}

\author{
Prototype Direct Mail Letter One \\ Representing Moves and Structural Elements \\ Which Occurred in $\geq 85 \%$ of the Corpus
}

\begin{tabular}{|c|c|c|}
\hline $\begin{array}{l}\text { Structural } \\
\text { Element C }\end{array}$ & \multicolumn{2}{|c|}{ Dear Chip En } \\
\hline Move 2 & \multicolumn{2}{|c|}{$\begin{array}{l}\text { Now more than ever, inner city girls need your support to help their dreams } \\
\text { become a reality. } \\
\text { Each generation of girls faces new challenges: new technology, new moral } \\
\text { issues, new opportunities. Inner City Girls experience a wide range of real } \\
\text { life skills - first aid, resume writing, and managing money. They also reap } \\
\text { benefits that are difficult to measure, including enhanced self-esteem, greater } \\
\text { confidence in their abilities, and the strength and conviction to take the lead } \\
\text { and excel in their endeavors. } \\
\text { We start early. As a preventative, informal education program, Inner City } \\
\text { Girls helps girls relate to others, develop values, contribute to their society, } \\
\text { and develop their own potential. This results in reduced risk of teen } \\
\text { pregnancy, suicide, truancy, substance abuse and so many other crises. }\end{array}$} \\
\hline Move 3 & \multicolumn{2}{|c|}{$\begin{array}{l}\text { Your gift to the } 1997 \text { Inner City Girls Annual Campaign helps to ensure that } \\
\text { girls will continue to receive the benefits that Inner City Girls offers. } \\
\text { Today's girls will be tomorrow's leaders - and they are counting on you. }\end{array}$} \\
\hline $\begin{array}{l}\text { Structural } \\
\text { Element D }\end{array}$ & \multicolumn{2}{|l|}{ Sincerely, } \\
\hline $\begin{array}{l}\text { Structural } \\
\text { Element E }\end{array}$ & (Signature) & $\begin{array}{l}\text { Clipboard08 - IffanView (Zoom: } 954 \times 863 \text { ) (Selection: } \\
145,317 ; 405 \times 66 ; 6.136)\end{array}$ \\
\hline $\begin{array}{l}\text { Structural } \\
\text { Element F }\end{array}$ & \multicolumn{2}{|c|}{$\begin{array}{l}\text { Sally Mentor } \\
\text { President } \\
1997 \text { Inner City Girls Annual Campaign } \\
\end{array}$} \\
\hline
\end{tabular}




\title{
Appendix 2
}

\author{
Prototype Direct Mail Letter Two \\ Representing Moves and Structural Elements \\ Which Occurred in $\geq 50 \%$ of the Corpus
}

\begin{tabular}{|c|c|}
\hline $\begin{array}{l}\text { Structural } \\
\text { Element A }\end{array}$ & October 26,2000 \\
\hline $\begin{array}{l}\text { Structural } \\
\text { Element B }\end{array}$ & $\begin{array}{l}\text { Sam Q. Doe } \\
123 \text { Street Dr. } \\
\text { Somewhere, IN } 46202\end{array}$ \\
\hline $\begin{array}{l}\text { Structural } \\
\text { Element C }\end{array}$ & Dear Sam, \\
\hline Move 2 & $\begin{array}{l}\text { For many of the children and seniors that Help Your Neighbor cares for, } \\
\text { the Holiday season can be a troubling time. Nearly every day HYN receives } \\
\text { a call about a patient or family in need of home care who has limited financial } \\
\text { resources. Calls for help from families that need the crisis services HYN } \\
\text { provides for their children ring throughout the season. This is not the } \\
\text { ringing that you and I traditionally picture during the holiday season. }\end{array}$ \\
\hline Move 3 & $\begin{array}{l}\text { But there is something that you can do to help. With your gift of } \\
\text { sharing, you are: } \\
\text { "providing needed home care services to the most needy } \\
\text { *giving emergency respite to families of children at risk for neglect } \\
\text { or abuse } \\
\text { "helping establish a "Golden Touch" program to provide } \\
\text { companionship and homemaker services to homebound seniors. }\end{array}$ \\
\hline Move 2 & $\begin{array}{l}\text { Help Your Neighbor has been a part of this community for over } 85 \\
\text { years. Serving the needy has been an important part of our mission. Over } \\
\text { the last ten years, HYN has delivered over } \$ 1 \text { million worth of free services } \\
\text { to the citizens of Somewhere. }\end{array}$ \\
\hline $\begin{array}{l}\text { Move } 3 \\
\text { Move } 5 \\
\end{array}$ & $\begin{array}{l}\text { But we cannot do it alone. We need your help. A gift of sharing can } \\
\text { bring comfort and hope to those most in need during this holiday season. } \\
\text { Please use the enclosed envelope to make a contribution to help us ease the } \\
\text { suffering and indeed ring in a most joyous holiday season. }\end{array}$ \\
\hline Move 6 & I thank you for your generous support. \\
\hline $\begin{array}{l}\text { Structural } \\
\text { Element D }\end{array}$ & Sincerely, \\
\hline $\begin{array}{l}\text { Structural } \\
\text { Element E }\end{array}$ & (Signature) \\
\hline $\begin{array}{l}\text { Structural } \\
\text { Element F }\end{array}$ & $\begin{array}{l}\text { Bob L. Brown } \\
\text { President \& CEO }\end{array}$ \\
\hline
\end{tabular}




\section{Appendix 3}

Prototype Direct Mail Letter Three

Representing All Possible Moves and Structural Elements

\begin{tabular}{|c|c|}
\hline $\begin{array}{l}\text { Structural } \\
\text { Element A }\end{array}$ & October 26,2000 \\
\hline Move 1 & $\begin{array}{l}\text { "Do all the good you can, by all the means you can, in all the ways you can, } \\
\text { in all the places you can, at all the times you can, to all the people you can, } \\
\text { as long as ever you can." John Wesley }\end{array}$ \\
\hline $\begin{array}{l}\text { Structural } \\
\text { Element B }\end{array}$ & $\begin{array}{l}\text { Sam Q. Doe } \\
123 \text { Street Dr. } \\
\text { Somewhere, IN } 46202\end{array}$ \\
\hline $\begin{array}{l}\text { Structural } \\
\text { Element C }\end{array}$ & Dear Sam, \\
\hline Move 2 & $\begin{array}{l}\text { Ebenhazer cares for at-risk children and families. We do this through a } \\
\text { wide range of programs including community-based, therapeutic foster care, } \\
\text { group homes and our treatment center. Many of the children are victims of } \\
\text { abuse or live in unstable homes. }\end{array}$ \\
\hline Move 3 & $\begin{array}{l}\text { This Christmas season we are asking you to take a few minutes to } \\
\text { consider making a contribution to Ebenhazer to help the } 1,500 \text { children and } \\
\text { families that we care for. }\end{array}$ \\
\hline Move 2 & $\begin{array}{l}\text { Many of the children have no homes; no memories of joy from past } \\
\text { holidays. Others are from families that are struggling to provide a healthy, } \\
\text { happy environment but don't have the resources to make it possible. }\end{array}$ \\
\hline$\frac{\text { Move } 5}{\text { Move } 4}$ & $\begin{array}{l}\text { Your contribution will make a difference in a child's life. It may help a } \\
\text { family stay together. It can certainly make happy holiday memories. } \\
\text { A gift to Ebenhazer means the children in our care will have presents to } \\
\text { open. A gift means a family will have a holiday meal, cooking utensils to } \\
\text { prepare the meal and dishes to serve it on. Your gift will go beyond the } \\
\text { holiday season. It can help purchase clothing, school supplies, books and } \\
\text { educational tools throughout the year. } \\
\text { Please use the enclosed donation card and return envelope and mail your } \\
\text { tax-deductable donation to Ebenhazer today. }\end{array}$ \\
\hline Move 6 & Thank you in advance for your gift. \\
\hline Move 7 & We wish you and your family a new year full of joy and love. \\
\hline $\begin{array}{l}\text { Structural } \\
\text { Element D }\end{array}$ & Sincerely, \\
\hline $\begin{array}{l}\text { Structural } \\
\text { Element E }\end{array}$ & (Signature) \\
\hline $\begin{array}{l}\text { Structural } \\
\text { Element F }\end{array}$ & $\begin{array}{l}\text { Mary Smith } \\
\text { Director }\end{array}$ \\
\hline Move 3PS & $\begin{array}{l}\text { P.S. Let our families and children know that you want them to have the } \\
\text { same kind of memories of the holidays that you will have. Please give } \\
\text { generously. }\end{array}$ \\
\hline Move 6PS & Thank you for thinking of Ebenhazer this Christmas season. \\
\hline $\begin{array}{l}\text { Structural } \\
\text { Element G }\end{array}$ & Enclosures \\
\hline
\end{tabular}




\section{REFERENCES}

1. Abelen, E., G. Redeker, et al. (1993). "The rhetorical structure of U.S.-American and Dutch fundraising letters.” Text 13(3): 323-350.

2. Bazerman, C. (1997). Some informal comments on texts mediating fund-raising relationships: Cultural sites of affiliation. Written discourse in philanthropic fund raising. Issues of language and rhetoric (pp. 17-26). Indiana University Center on Philanthropy._Working Papers, 98-13. Indianapolis, IN.

3. Bhatia, V. K. (1993). Analysing Genre: Language Use in Professional Settings. London: Longman.

4. Bhatia, V. K. (1997). Discourse of philanthropic fund-raising. Written discourse in philanthropic fund raising. Issues of language and rhetoric (pp. 27-44). Indiana University_Center on Philanthropy. Working Papers, 98-13. Indianapolis, IN.

5. Bhatia, V. K. (1998). Generic patterns in fundraising discourse. New Directions for Philanthropic Fundraising, 22, 95-110.

6. Biber, D., Conrad, S., \& Reppen, R. (1998). Corpus linguistics investigating language structure and use. Cambridge, UK: Cambridge University Press.

7. Cone, A. L. (1987). How to create and use solid gold fund-raising letters. Ambler, PA: Fund-Raising Institute.

8. Connor, U. (1997). Comparing research and not-for-profit grant proposals. Written discourse in philanthropic fund raising. Issues of language and rhetoric_(pp. 45-64). Indiana_University Center on Philanthropy. Working Papers, 98-13. Indianapolis, IN.

9. Connor, U. (2000). Variations in rhetorical moves in grant proposals of US humanists and scientists. Text, 20 (1), 1-28.

10. Connor, U., \& Mauranen, A. (1999). Linguistic analysis of grant proposals: European Union research grants. English for Specific Purposes, 18 (1), 47-62.

11. Connor, U. \& Wagner, L. (1998). Language use in grant proposals by nonprofits: Spanish and English. New Directions for Philanthropic Fundraising: Understanding and Improving the Language of Fundraising, 22, 59-73.

12. Crismore, A. (1997). Visual rhetoric in an Indiana University Foundation "Annual Report.” Written discourse in philanthropic fund raising. Issues of language and rhetoric (pp. 64-100). Indiana University Center on Philanthropy. Working Papers, 98-13. Indianapolis, IN.

13. Dudley-Evans, T. (1995). "Genre models for the teaching of academic writing to second language speakers: Advantages and disadvantages.” The Journal of TESOL France 2 (2): 181-193.

14. Flowerdew, L. (1998). Corpus linguistic techniques applied to textlinguistics. System, 26, 541-552.

15. Graves, R. (1997). Dear friend (?): Culture and genre in American direct marketing letters. Journal of Business Communications, 34 (3), 235-252.

16. Kelly, K. (1997). From motivation to mutual understanding. Shifting the domain of donor research. In D. E. Burlingame (Ed.), Critical issues in fund raising (pp. 81-109). New York: John Wiley \& Sons, Inc.

17. Lauer, J. (1997). Fundraising letters. Written discourse in philanthropic fund raising. Issues of language and rhetoric (pp. 101-108). Indiana University Center on Philanthropy. Working Papers, 98-13. Indianapolis, IN.

18. Leech, G. (1991). The state of the art in corpus linguistics. In K. Aijmer \& B. Altenberg (Eds.), English Corpus Linguistics: Studies in Honour of Jan Svartik (pp. 8-29). London: Longman.

19. Lewis, H. G. (1997). Direct mail fund raising tactics. Direct Marekting, 59, 28-30.

20. McCagg, P. (1997). Metaphorical morality and the discourse of philanthropy. Writtendiscourse in philanthropic fund raising. Issues of language and rhetoric (pp. 109-120). Indiana University 
Center on Philanthropy. Working Papers, 98-13. Indianapolis, IN.

21. Myers, G. (1997). Wednesday morning and the millenium: Notes on time in fund-raising texts. Written discourse in philanthropic fund raising. Issues of language and rhetoric (pp. 121-134). Indiana University Center on Philanthropy. Working Papers, 98-13. Indianapolis, IN.

22. Payton, R. L., Rosso, H. A., \& Tempel, E. R. (1991). Toward a philosophy of fund raising. In D. E. Burlingame \& L. J. Hulse (Eds.), Taking fundraising seriously: Advancing the profession and practice of raising money_(pp. 3-17). San Francisco: Jossey-Bass.

23. Swales, J. M. (1981). Aspects of article introductions. Aston ESP Research Report No. 1, Language Studies Unit, University of Aston in Birmingham, Birmingham, UK.

24. Swales, J. M. (1990). Genre Analysis: English in Academic and Research Settings. Cambridge, England, Cambridge University Press.

25. Torre, L. \& Bendixen, M. A. (1988). Direct Mail Fund Raising: Letters That Work. New York: Plenum Press. 